\title{
The Effect of ZnO Nanoparticles on the Color Change of Polyester
}

\author{
ZHAO WANG \\ Department of Nanoscience and Technology, Beijing, China. \\ *Corresponding author E-mail: z14ho.wang@gmail.com \\ http://dx.doi.org/10.13005/ojc/370132
}

(Received: January 09, 2021; Accepted: February 10, 2021)

\begin{abstract}
In this study, the effect of adding zinc oxide nanoparticles $(\mathrm{ZnO})$ on the general color change and transparent adhesion strength of polyester folds was studied in wood (Ulmus glabra). Zinc oxide nanoparticles with concentrations of $0,0.22,0.20,1,1.20$ and $2 \%$ of coating weight were combined. In a study about adherence resistance of coating the results showed that the highest adhesion in nano coatings contained $1 \%$ nanoparticles of zinc oxide, and adding more than this had a negative effect on the adhesion of coating. In the case of general color change, the addition of zinc oxide nanoparticles is also caused a change in the color of samples coated with nanoparticles. However, in small amounts of nanoparticles, color changes were made and the brightness reduction was not significant.
\end{abstract}

Keywords: ZnO Nanoparticles, TEM, Color change polyester.

\section{INTRODUCTION}

Wood resisting against destructive factors is one of the issues that has been considered since the past. The reason for this is the enormous use and its important role that wood plays in human life. Wood is a natural material used for centuries to build houses, home decoration, furniture, doors and windows, wooden artwork, wooden flooring and many more (Lowden and Hull, 2013). Technology advancement and the possibility of wood processing have increased the use of wood in various industries, and according to the needs of each industry, the unique features of wood can be used. Wood has properties like heterogeneous, and especially absorbing moisture. Moisture absorption is making wood a suitable environment for the growth of biodegradable factors, which, in addition to reducing its beauty, also causes the destruction of wooden structures (Budakci, 2010; Sjostrom, \& Korkut; 2010). Creating suitable conditions for increasing wood resistance against the effects of physical and mechanical factors (sunlight, water and humidity, heat, aging, etc.), increases the useful life, improves the various properties of wood and its proper use. In recent decades, by supplying new colors and coatings that has high protection, more expectations have been made for extending the useful life of natural materials such as wood. By applying suitable coatings on wood surfaces, moisture absorption decreased, the durability and stability of wood stabilized and useful life of the wood will increase. As a result, the use of wood can be developed and improved by increasing ultimate strength.

On the other hand, according to studies, the

This is an Open Access article licensed under a Creative Commons license: Attribution 4.0 International (CC- BY). Published by Oriental Scientific Publishing Company @ 2018

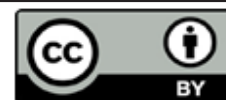


use of suitable nanoparticles can play an important role in improving wood properties. Protective and coating properties can be improved by using nanoparticles. Nanoparticles, when uniformly dispersed in a coating area and form a stable dispersion, have the ability to Improve characteristics such as adhesion, moisture resistance, aging and temperature, and resistance to atmospheric factors in coatings (Kaygin and Akgun, 2008, Kaygin and Akgun, 2009). Improved coatings with nanotechnology can then be used as an appropriate protective layer on the surface of the wood. In many cases, these coatings, in addition to the protective role, cause no discoloration and apparent coating quality due to the small size of nanoparticles (Chen et al 2004; Silivane and Ocheane 2008.)

An internationally lucrative industry in wood industry and its specialty products is the wooden furniture industry. Among the important fields in wooden furniture industry, the coatings used to cover these wooden products due to their short life and short periods of coating renovation and transparent quality of internal folds used to cover these products. For this reason, according to improve the quality of internal folds has great importance. On the other hand, one of the properties that is important in terms of wood products life and their durability is the stickiness of coating to the surface of wood. As Khojasteh, Khosro and Ghofrani (2014) stated in their study that adhesion resistance of coating to the wood surface is one of the most effective and influential factors on the durability of wood products. Miszczyk and Schauer (2005) also find that coating's adhesion to its substrate is one of the important protective feature of coating. This indicates the importance of strengthening the adhesion resistance of applied coating on wood surface. In this regard, as well as studies on the effect of zinc oxide nanoparticles on coating properties, a study has not yet been made on the effect of zinc oxide nanoparticles on the adhesion resistance of coating to wood surface. Therefore, due to the importance of evaluating the effective factors on improving the adhesion resistance of coating to wood surface, the present study examines the effect of adding zinc oxide nanoparticles on the adhesion strength of coating as well as the general color change of Nano coatings compared to the control coating.

\section{MATERIALS AND METHODS}

\section{materials}

The wooden species studied in this research was a species of mulch with a specific mass of $0.63 \mathrm{~g} /$ $\mathrm{cm}^{3}$. The dimensions of wood samples were from $20 \mathrm{x}$ $100 \times 170 \mathrm{~mm}$. The final equilibrium moisture content of prepared specimens was considered to be $8 \%$. According to the importance of using healthy samples in the tests, the selected samples have normal growth conditions, free of any cracks, gaps, dead and living nods, reactive wood, crooked, rot, etc.

The transparent fold used in this study was based on the polyester (polyester) coating made from the Bajak chemical company. This coating was consisted of two acrylate polyol based on Acrylic and polyisocyanate hardeners. The physical properties of these polyol and poly-isocyanate hardeners provided by Bajak chemical company are respectively presented in Tables 1 and 2. To adjust viscosity of polyester coating, a $99.5 \%$ pure toluene solvent and a specific mass of $0.85 \mathrm{~g} / \mathrm{cm}^{2}$ were used.

The nanoparticles used in this study were zinc oxide nanoparticles ( $\mathrm{ZnO}$ ) from the American company. In Table 3, the Nano-particles of Nanomatrix zinc oxide were presented.

\section{Preparation of Nano Coatings}

To make Nano coatings, first, a solid percentage of transparent polyol component of polyester folds by adding toluene solvent to 40 Weight percentage was reduced. Controlling and measuring the solid percentage transparent of polyester folds was performed according to standard ASTM D-2832 (2014). After reducing the solid percentage of polyol component, zinc oxide nanoparticles powder was added with a weight ratio of $0.25,0.50,1,1.50$, and $2 \%$ and 2 as compared to solid polyol. For initial mixing of nanoparticles with polyester resin, a magnetic stirrer at 1000 rpm was used. For proper dispersion and stabilization of nanoparticles in polyol resin, an ultrasonic device with a time of $45 \mathrm{~min}$ 0.6 frequency and a power of $70 \%$ was used. To study the effect of zinc oxide nanoparticles on the color change and adhesion resistance of coating, a coating without a Nano (control coating) was also prepared to cover the samples surface. The degree of polyisocyanate hardener use in coating prior to application were $22 \%$ of coating mass. 
Imaging with transmitted electron microscope

Transmitted electron microscope was used to study the dispersion and distribution of zinc oxide nanoparticles in polyester coatings bed. For this purpose, at first, Nano coatings were provided with a free film coating (thin layer of coating). Coatings containing 1 and $2 \%$ of zinc oxide nanoparticles were applied to the surface of non-contaminated glasses by filtration film with a thickness of 200 microns to provide free film coatings. After completely drying the coatings, free films were removed from the glass surface by using hot water. Then, from free films, layers with a thickness of about 100 nanometers for TEM imaging were prepared by Ultra microtome Reichert-OmU-3 device. Imaging with a transmitted electron microscope was carried out at the Faculty of Air and Space in Khaje Nasir-e-Al-Din Tusi University by using a TEM device by characteristics of Zeiss-EM10C-80KV.

\section{Measuring color change}

Measurement of samples color change was performed by using a spectrophotometer equipped with Optical Multifunction 65 based on standard ASTM D-2244 (2011) with 6 replications for each sample. Indicators provided by device, $L^{*}, a^{*}, b^{*}$ in which the brightness factor of the samples varies from 0 (darkness) to 100 (white). Also, $a^{*}$ indicators show redness $\left(+a^{*}\right)$ to green $\left(-a^{*}\right)$ and $b^{*}$ yellowing $\left(+b^{\star}\right)$ to blue $\left(-b^{\star}\right)$ of samples (Fig. 1). In order to compare the color intensity of samples, was used. This factor is obtained from relation 1 of the second root $\Delta \mathrm{L}^{*} \Delta \mathrm{a}{ }^{*}, \Delta \mathrm{b}$. $\Delta \mathrm{E}$ factor was calculated in two steps in order to compare the total color change of coated samples with uncoated sample as well as the total color change of coatings covered with Nano coatings containing different percentages of zinc oxide nanoparticles with a control coating.

\section{Statistical design}

To analyze the results, SPSS software version 22(2013) was used. To study the effect of zinc oxide nanoparticles on overall color change and coating adhesion resistance, the results were analyzed by using a factorial experiment in a completely randomized design. Duncan's multidomain test was used to compare the mean of groups. ImageJ analysis software version 1/48 was used to obtain the level of isolated wood along with the surface coating of wood (surface deflection level) and cohesion.

\section{RESULTS}

\section{Transmitted electron microscope images}

The distribution of zinc oxide nanoparticles with 1 and $6 \mathrm{wt} \%$ nanoparticles relative to poly solid percentage was investigated by using transmitted electron microscopy imaging. In Fig. 1, the TEM image obtained from the study of zinc oxide nanoparticles distribution in Nano coating containing $2 \%$ Nano is presented. As seen in this figure, nanoparticles have been well dispersed in polyester coating and created a uniform structure in this coating. The average nanoparticle size in nano coatings containing $1 \%$ Nano is $17+4$, but increasing the amount of zinc oxide nanoparticles up to $3 \%$ results in incorrect mixing of nanoparticles in coating .

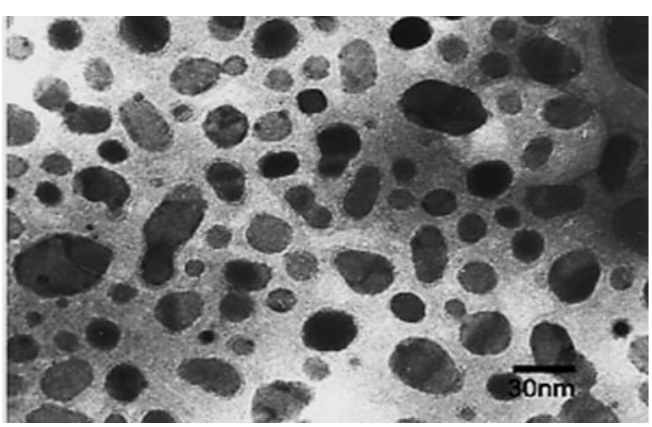

Fig. 1. TEM image from coating containing $4 \%$ Zinc oxide nanoparticles

\section{Overall color change}

The results of overall color change measurement in coating samples compared to the non-coated samples indicated that addition of zinc oxide nanoparticles to polyester coating reduced the color difference of coated samples in compared to non-coated samples, so that the lowest color difference was observed in nano coatings containing $2 \%$ Nano in compared to non-coated wood samples. Duncan's grouping also showed that control coating was placed with the highest color difference and A was compared to non-coated sample in coating group containing $2 \%$ zinc oxide nanoparticles with the lowest color change compared to non-coated sample was placed in group $\mathrm{E}$.

The results for the effect of addition of nanoparticles zinc oxide on the amount of overall color change of coatings samples with Nano coatings in compared to control coating samples showed that addition of nanoparticles to the polyester coating contributed to a change in the color of Nano coatings 
in compared to the samples with control coating. The highest color change was observed in Nanocoatings containing 1.20 and $2 \%$ Nano that Duncan's grouping also made these Nano-coatings with the highest color change in compared to the control coating in Group A. The study about comparison of adhesion strength and the wood separation percentage with coating and the correlation between the adhesion resistance of coating and wood deflection surface also showed that there is a direct correlation between adhesion strength of coating and wood deflection surface in the mulch samples. As the adhesion resistance of coating to the surface of wood increases, the highest level of deflection and detachment occurs in the wood.

\section{Overall color change}

In the study about the effect of zinc oxide nanoparticles on the overall color change of coatings, it was observed that the addition of these nanoparticles caused a change in coating color compared to the control coating and reduced the coverage brightness in these coatings (Nano coatings). One of the main reasons for color change of Nano coatings containing zinc oxide nanoparticles in compared to control coating is the 0.50 -unit difference in deflection index between nanoparticles (1.49-1.56) and polyester coating (2.008); but on the other hand, it was found that the overall effect of small quantities of nanoparticles on color change of coating was on the contrary was low. The reason for this is the proper dispersion of a relatively complete dispersion of nanoparticles into the polyester coating and the creation of a uniform structure with this coating. With proper dispersion of nanoparticles in coating, and according to the small size of nanoparticles (less than $200 \mathrm{~nm}$ ), visible light can pass through the coating without being spread and dispersed, with slight variations in the color of the coating (Moradian and Kashani, 2010). A study about dispersion of nanoparticles by TEM image in nanoparticles containing $1 \%$ nano also showed that nanoparticles are well dispersed in Nano coating and their particle size is less than $200 \mathrm{~nm}$ $(117+40.1 \mathrm{Nm})$; However, the increase in the number of nanoparticles in coating, the greatest change in color created in the coating was observed. One of the main reasons for the increase in color change in coatings containing high amounts of Nano 1 and 2 percent of zinc oxide nanoparticles can be the accumulation of nanoparticles in polyester coating.
With accumulation of nanoparticles in coating, masses of nanoparticles with dimensions greater than $200 \mathrm{~nm}$ in the coating are created, which allow the aggregation to propagate and disperse visible light, which causes the coating to be coated and bleached, and the brightness of coating in this Nano coating is more affected. The results of TEM image also confirmed that nanoparticles were not properly distributed in Nano-coatings containing $2 \%$ Nano (nanoparticles size was $265+86.1 \mathrm{~nm}$ ). Moradian and Kashani (2010) also in their study on the effect of alumina nanoparticles on color change of coating, stated that in small amounts of these materials, nanoparticles, due to their smaller dimensions of 0.2 micrometers $(200 \mathrm{~nm})$, created color change in Nano coatings are low in high concentrations. Ajayan et al., (2006) also stated that the main reasons for color change and reduced transparency due to the addition of nanoparticles in polymeric bed is the difference in deflection index of nanoparticles and resin, and also the formation of nanoparticle accumulation masses in the polymeric bed.

\section{CONCLUSION}

The results obtained from the effect of zinc oxide nanoparticles on adhesion resistance of the coating showed that the addition of these nanoparticles improved the adhesion resistance of coating. In general, it can be concluded that the coherence of coating has a direct relation with adhesion of coating in Pull-off method. Accordingly, by improving adhesion resistance by adding zinc oxide nanoparticles, it can be stated that by adding nanoparticles to coating, the cohesion of coating is also increased, which results in improved adhesion resistance of coating. As regards the amount of zinc oxide nanoparticles, it was found that by adding $1 \%$ Nano, the highest adhesive resistance of coating is achieved, and adding more than this amount results in a decrease in adhesion resistance. The reason for this can be attributed to the distribution of nanoparticles in matrix of polyester coatings. As shown in microscopic examination, the coating containing $1 \%$ zinc nanoparticles is well-dispersed and does not exceed the size of nanoparticles in this coating of $200 \mathrm{~nm}$. Such a uniform dispersion increases the mechanical strength of Nano coating and, consequently, its cohesion. Since the adhesion measurement by 
pull-off method has a direct effect on the results, it is observed that Nano coating sample containing $1 \%$ nano particales has the highest adhesion values; However, by increasing nanoparticles up to $2 \%$, the dispersion of nanoparticles decreased, so that at $2 \%$ nanoparticles, the particles only appear as masses of nanoparticle accumulation in coating, which has a significant effect on the decrease of coating continuity that its direct consequence is to reduce the adhesion resistance in these Nano coatings.

\section{ACKNOWLEDGEMENT}

The author is grateful to Science Research and Technology, China.

\section{Conflicts of Interests}

The author declares no conflict of interest.

\section{REFERENCES}

1. Bavykin, D.V.; Friedrich, J.M.; Walsh, F.C. $A d v$. Mater., 2006, 18, 2807-2824.

2. Ravindra,V.G.; Pratiks, K.; Prakash, A.M.; Pradeep T.G. Int. Jour. Adh., 2019, 95, 102427.

3. Thi, N.L.; N, TrucV.D.; Thien, V.N.; Phi, H.D.; Van, T.T.; Van, P.M.; Anh, H.N.; Duc, A.D.; Tuan, A.N.; Thi, K.A.V.; Dai, L.T.; Trong, L.L. Prog. Organ. Coat., 2018, 132, 15-20.

4. Fengwei, X.; Tianlong, Z.; Peter, B.; Valsala,K.B. J. Prog. Poly. Sci., 2019, 90, 211-268.

5. Lisa,T.; Tim, G.M.; Raju, A.; François, M.; Ranjith, J.; Ian, G.; Pathiraja A.G., Biomater.,
2007, 36, 5407-5417.

6. Sylwia, C.; Massimo, F.B.; Krzysztof, S. Poly. Test., 2018, 68, 135-145.

7. Saran, S.; Manjari, G.; Devipriya, S. P., Clean. Prod., 2018, 177, 134-143.

8. Yan, Z.; Fu, L.; Zuo, X.; Yang, H., Appl Catal B-Environ., 2018, 226, 23-30.

9. Khrizanforov, M. N.; Fedorenko, S. V.; Mustafina, A. R.; Kholin, K. V.; Nizameev, I. R.; Strekalova, S. O.; Grinenko, V. V.; Gryaznova, T. V.; Zairov, R. R.; Mazzaro, R., Dalton Transactions., 2018, 47, 9608-9616. 